Preprints of the

Max Planck Institute for

Research on Collective Goods

Bonn 2007/21

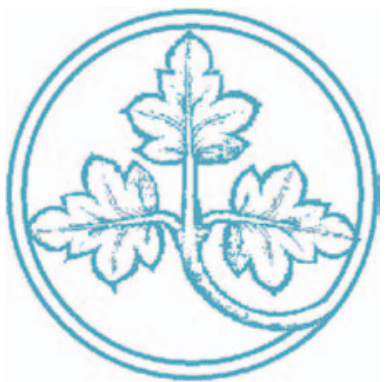

The (de)composition of firms: Interdependent preferences of corporate actors

Andreas Nicklisch

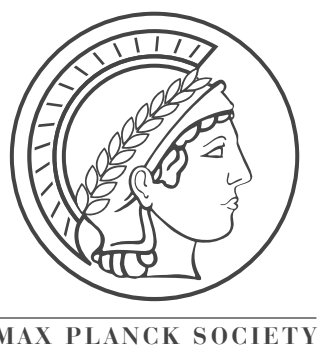




\section{The (de)composition of firms: Interdependent preferences of corporate actors}

Andreas Nicklisch

November 2007 


\title{
The (de)composition of firms: Interdependent preferences of corporate actors*
}

\author{
by \\ ANDREAS NiCKLISCH ${ }^{\dagger}$
}

November 13, 2007

\begin{abstract}
This article discusses the limitations of the orthodox economic theory of the firm as a nexus of contracts. Various experimental studies have shown that the aggregation of individuals in groups changes behavior and preferences systematically. This perspective has been formalized by models of interdependent preferences. Based on a prominent approach of interdependent preferences, intention-based preferences, two types of labor contracts, incentive contracts and bonus contracts, are analyzed. Results are compared with the predictions of the orthodox economic theory. (JEL: D21, D63, L14)
\end{abstract}

Keywords: Firms, interdependent preferences, labor contracts

${ }^{*}$ I would gratefully like to acknowledge helpful advice by C.C. von Weizsäcker, M. Hellwig, and C. Engel.

${ }^{\dagger}$ Max Planck Institute for Research on Collective Goods, Kurt-Schumacher-Straße 10, 53113 Bonn, Germany; Email: nicklisch@coll.mpg.de 
There is an important mismatch between the purpose of this article and the standard approach of economics. Economic theory rests on the concept of methodological individualism. All activities within an economic system can be traced back to decisions of individuals. States do not choose, firms do not produce, and parties do not rule the country; individual members of the state, the firm, or the party do. Thus, the economic perspective on corporate actors is one of a cooperation of individual actors. However, the purpose of this article is to provide the reader with some evidence why this perspective is incomplete. Corporate actors represent more than the sum of individual actors. By doing so, the challenge for the author of this article is not to violate his economic origin and, therefore, to maintain the methodological individualism.

Among the multitude of real-world examples for corporate actors, this article centers on the firm. In economics, firms are typically analyzed typically alongside their counterparts, households. Firms provide the economy with goods, households consume the goods. Astonishingly, much intellectual effort has been devoted to reduce the level of aggregation of firms' decisions, whereas households still represent some aggregation of individuals. Economists know little about the aggregation of preferences within a family. A more individualistic approach for consuming individuals is probably needed, but I prefer not to discuss this issue. Rather, I start at the opposite end by analyzing firms. A precise theory has been developed to describe the behavior of individuals within firms (an early example is Coase, 1937). My contribution to this tradition will be an analysis of the firm where we allow for aggregation of individuals in firms to change behavior and preferences systematically. So instead of bilateral short-term interactions of individuals on markets, I will consider long-term interactions among, typically, several individuals.

A very individualistic definition characterizes the firm as the nexus of contracts (Jensen \& Meckling, 1976). Firms are reduced to a bundle of relations among individuals. A very prominent example for this perspective has been offered by Holmstrom (1982) in his seminal article on teamwork, which will be presented in Section 1. However, teamwork and cooperation create substantial values to the firm which are incompatible with the nexus of contracts perspective. A richer picture of firms can be provided by extending preferences so that the subject has preferences for individual income distributions, as well as with respect to income distributions of other group/firm members. The basic concepts of interdependent preferences will be discussed 
in Section 2. Finally, Section 3 will analyze the issue of labor contracts in the context of interdependent preferences. Section 4 concludes the article.

\section{The decomposition of the firm}

Economic cooperation is a matter of super-additivity. Peasants increase their harvest by cooperation and specialization. Teams of specialized workers are more productive than the same number of workers acting on their own. Today, labor division is typically organized in firms. Particularly, organizing the production in firms leads to a separation of ownership and control of the firm's assets. Employees control assets of the firm, for instance production means, intellectual property rights, or working time, while the employer cannot directly control the decisions of employees, since control raises costs which are usually referred to as agency costs (e.g., Jensen \& Meckling, 1976). The means to organize indirect control of employers over assets are contracts. Contracts specify individual rights as to how production costs and rewards will be allocated among the participants. Each of the involved parties tries to maximize her monetary earnings while negotiating for the contract. According to orthodox economic theory, contracts provide the comprehensive characterization of firms. Consequently, speaking about an economic analysis of firms reduces the debate to an analysis of contracts and the resulting incentives for the involved contract parties. Although this approach describes the firm rather poorly from the perspective of other disciplines, for instance law or sociology, I will not extend the approach. I will show that minor modifications concerning the motives of individual actions is sufficient to make this approach much more realistic, even from the perspective of noneconomists. The outset of my analysis will be the orthodox economic model of team production within a firm proposed by Holmstrom (1982). For reasons of simplicity, I will consider the firm-worker problem as if there were only one period of interaction. Notice, however, that for an interaction that takes place for a finite number of periods (and human life is finite), the analysis would not change substantially. I will present the analysis in two subsidiary ways. First, I will describe the problem in non-technical notation. Second, I will introduce subsequently the standard economic notation (emphasized in italics). The non-technical way is less precise, but it allows the inexperienced reader to follow the discussion.

A firm owner employs $n$ workers. Workers choose certain actions that 
influence the productivity of the firm. Increasing the workers' activities increases productivity, but also increases nonmonetary costs like pain or effort for workers. The firm owner cannot directly observe the actions workers choose. However, the production is observable. There is a certain bundle of actions, $a^{*}$, which maximizes the surplus of production, that is, the difference between the monetary outcome of the firm's production and the sum of work costs.

Suppose there are $n$ employees and one employer. Each employee takes a non-observable action $a_{i} \in \mathcal{A}_{i}=[0, \infty)$. Actions incur private costs, $c_{i}: \mathcal{A}_{i} \rightarrow \mathbb{R} ; c_{i}$ is strictly convex and increasing in $a_{i} . a=\left(a_{1}, a_{2}, \ldots, a_{n}\right) \in$ $\times_{i=1}^{n} \mathcal{A}_{i}$ denotes the vector of actions chosen by all employees. Furthermore, actions determine the monetary outcome of the firm's production, $x: \times_{i=1}^{n} \mathcal{A}_{i} \rightarrow \mathbb{R} . \quad x$ is observable for the employer and increases strictly concave with $x(0)=0$. Actions satisfy Pareto optimality, $a^{*}$, if

$$
a^{*}=\arg \max _{a}\left[x(a)-\sum_{i=1}^{n} c_{i}\left(a_{i}\right)\right] \text {. }
$$

The firm owner has to offer contracts which specify the actions such that all workers will accept their contracts and no worker has an incentive to deviate with his action from the specification; that is, the contract specifies a Nash equilibrium. Workers will only accept contracts if the contracts compensate at least their working costs (otherwise, workers are better off if they leave the firm). Implementing the bundle that maximizes the distance between the production surplus and the sum of working costs is in the best interest of the firm owner. On the other hand, the bundle $a^{*}$ must be attractive for workers, so that they choose $a^{*}$ even without being directly controlled by the owner. Consequently, the owner seeks to design contracts that implement the action bundle $a^{*}$. One could ask which contract schemes implement $a^{*}$. Holmstrom (1982) has shown that - in general - a contract that divides the entire production surplus among workers irrespectively of the production result fails to do so.

Let $s_{i}(x)$ denote the share of the outcome that employee $i$ earns. One can think of a variable wage for $i$. Employee $i$ has a simple additive preference function that is linear in money and private working costs:

$$
u_{i}\left(s_{i}(x(a)), c_{i}\left(a_{i}\right)\right)=s_{i}(x(a))-c_{i}\left(a_{i}\right) .
$$


Suppose that $s_{i}(x(a)), x(a)$, and $c_{i}\left(a_{i}\right)$ are differentiable (Holmstrom (1982) can relax this assumption). Then, we may ask whether a sharing rule such as

$$
\sum_{i=1}^{n} s_{i}(x(a))=x(a)
$$

implements the Pareto-efficient action bundle $a^{*}$, that is, there is no firm owner and employees earn all the surplus of the firm. Employee $i$ optimizes his action choice $a_{i} \in \mathcal{A}_{i}$ with respect to $u_{i}\left(s_{i}(x(a)), c_{i}\left(a_{i}\right)\right)$. Maximizing equation (2) for $a_{i}$ yields

$$
s_{i}^{\prime} x_{i}^{\prime}-c_{i}^{\prime}=0
$$

where $x_{i}^{\prime}:=\partial x(a) / \partial a_{i}$. Pareto-optimality implies that $x_{i}^{\prime}-c_{i}^{\prime}=0$ (marginal productivity equals marginal costs) leading to $s_{i}^{\prime}=1 \forall i$. This conflicts with equation (3), since differentiation of (3) yields

$$
\sum_{i=1}^{n} s_{i}^{\prime}=1 .
$$

Equation (5) shows that employees earn only their share $s_{i}(x(a))$ of the marginal productivity, while each of them carries the full marginal costs for providing actions. Thus, this contract scheme does not yield Pareto-efficient production.

This result indicates free-rider problems, particularly for firms where workers form industrial cooperations without an independent firm owner. In other words, without a residual claimant (the firm owner), the contract scheme that distributes the production surplus among workers creates an incentive for workers to reduce effort in the hope that others will compensate this behavior. However, inefficient firms will be outcompeted on markets. The problem can be avoided by a slight modification of the payoff scheme. Let us assume that the firm owner offers workers a share of the production surplus only if they produce an outcome corresponding with a choice of $a^{*}$. Hence, workers receive a "take-it-or-leave-it" offer, whose shares exceed workers' costs. All workers know that they have to provide the action bundle $a^{*}$ in order to get the wage (which is strictly better than not working). So no worker has an incentive to deviate from the contract. 
Relaxing equation (3) to

$$
\sum_{i=1}^{n} s_{i}(x(a)) \leq x(a)
$$

provides a contract scheme that implements the Pareto-efficient action bundle $a^{*}$ as a Nash equilibrium. Particularly, the sharing rule

$$
s_{i}(x(a))= \begin{cases}k_{i} & \text { if } x(a) \geq x\left(a^{*}\right) \\ 0 & \text { otherwise }\end{cases}
$$

implements the Pareto-efficient action bundle $a^{*}$, where $k_{i} \geq c_{i}\left(a_{i}^{*}\right)>0$ and $\sum_{i} k_{i} \leq x\left(a^{*}\right)$. Notice that competition for employees among firms increases $k_{i}$, while oversupply of employees decreases $k_{i}$. Holmstrom (1982) provides an interesting extension of the problem that proves that discontinuous contract schemes like in equation (7) implement the Pareto-efficient action bundle $a^{*}$ even if the production outcome depends on random events.

In summary, firms are sufficiently characterized by the asset ownership of involved parties and the contracts formed between the parties (see, e.g., Grossman \& Hart, 1986). Firm ownership establishes a residual control right over the firm's assets whose existence guarantees optimal contractual design. Other authors (e.g., Hart \& Moore, 1990) have argued that owning residual control rights may also cause disadvantages. The analysis of disadvantages leads to a framework that allows to identify interactions which are best carried out within firms and interactions which are best carried out on markets, that is, without integration. Moreover, one can argue that firms have additional functions. For instance, equation (1) may not lead to a unique action bundle $a^{*}$. Several combinations of actions could provide efficient production. Thus, there can be the need for coordination among employees' action choices which could be offered by the employer. Yet, the general perspective of the orthodox economic theory on firms is reduced to coordination and control. Firms ensure production efficiency by means of bilateral contracts. Asset ownership determines the form of contracts among involved parties. No interactions within corporate actors, but only interactions among individuals are analyzed. In the following, I will provide some evidence suggesting that this perspective is inadequate to characterize the interactions within firms. 


\section{Interdependent preferences}

The critique on the orthodox perspective of the firms can be classified in two categories, an internal critique and an external critique. The internal critique centers on the question whether individuals within a group behave systematically differently than isolated individuals acting on their own. There is robust experimental evidence that there are substantial behavioral differences (e.g., see various examples in Kagel \& Roth, 1995). Let us consider two simple examples that show the systematic differences. Suppose you are offered one Euro. Would you accept or reject the Euro? Having a Euro is better than having none, so that one can assume that almost all of us would accept the Euro. The situation changes dramatically if the reader receives the additional information that an anonymous second player receives ten Euros. Out of the ten Euros, the second player offers you one Euro. If you accept the Euro, he or she will earn the remaining nine Euros. If you reject the Euro, neither you nor the second player receives any money. Remember that still having one Euro is better than having none. In fact, it is a dominant strategy to accept money. Yet, splitting the ten Euros one to nine is rather unfair. A large body of experimental studies has shown that the majority of players would reject this unfair split in the so-called ultimatum game (Güth, Schmittberger \& Schwarze, 1982). Individual behavior changes systematically even if they are matched with an anonymous second person. For the second example, consider that you are endowed with some money. You can either keep the money for your private consumption or you can invest it into a project. The investment is multiplied by a number smaller than one and returned to you. You can use the returns again for private consumption. Apparently, it is a dominant strategy not to invest into the project. Now consider the modification that within a group of players you are endowed with some money. You (and all other members of the group) may invest again - or not - in the project. Each player receives from the project the sum of all investments, multiplied by a number smaller than one. Still it is a dominant strategy not to invest into the project while hoping that some others (accidently) invest. Notice, if a player invests into the project, he or she voluntary provides a "positive externality" to the other group members. Other group members gain benefits from an investment whereas the costs for the benefits are borne by only one player. Experiments find that behavior changes dramatically (see, e.g., Isaac, McCue \& Plott, 1985). Players mutually provide positive externalities. 
The external critique is seemingly unrelated to the internal critique. One can argue that firms create some immaterial values which are nontransferrable and non-contractual (e.g., Cabral, 2000). It is important to differentiate between transferable and non-transferable immaterial values. Of course, a firm can sell brands or patents, but what about reputation or wellrehearsed production routines? Who owns these values, which firm member is responsible for the reputation of a firm? Reputation is a fragile value which can be harmed by almost any member of the firm. It is wrong to say that the firm owner holds the asset reputation. It is difficult to form contracts with respect to the firm's reputation; some elements can be found in British law which offers floating charges over the floating assets of a company. On the other hand, building up a reputation or establishing a rehearsed routine involves costs that firm owner and workers have to bear. Nonetheless, employers and employees do not negotiate on how much reputation has to be built up while bargaining over wages. Rather, employers provide additional salaries for experienced teams of workers. At this point, the internal and the external critique on the orthodox economic perspective of the firm are related. Interactions within a firm establish non-transferable, non-contractual values. They are established because individuals behave differently when interacting in groups than when they act on their own. For instance, employees create positive externalities for the entire firm by establishing well-rehearsed routines. On the other hand, employers pay extra wages for non-contractual attainments. It seems that employees and employers mutually exchange gifts (Akerlof, 1982) which create the extra value of the firm or the corporate actor.

How can this behavior be formalized? One could argue that the individuals develop some kind of group identity, and that this group identity determines the decisions of all group members. This idea, however, conflicts with the economic concept of methodological individualism. In contrast, I will consider a modification of the individual preference function such that individuals behave differently as group members than when they act in isolation. This leads to the approach of interdependent preferences (Sobel, 2005). Subjects draw utility not only from own payoffs, but also from payoffs of other group members.

The recent economic literature offers two prominent approaches of interdependent preferences, distributional preferences (e.g., Fehr \& Schmidt, 1999, Bolton \& Ockenfels, 2000), and intention-based preferences (e.g., Rabin, 1993, Dufwenberg \& Kirchsteiger, 2004, Falk \& Fischbacher, 2006). Notice that I denote all extended preferences as interdependent; others (e.g., Fehr \& 
Schmidt, 2006) differentiate between social preferences, for instance, distributional preferences, and interdependent preferences, for instance intentionbased preferences. According to distributional preferences, differences among own and other people's payoffs cause disutility to subjects. They exhibit aversion with respect to inequity. Notice that there are several recent studies which analyze theoretically employer-employee interactions within firms for subjects with distributional preferences (e.g., von Siemens, 2005, Demougin et al., 2006, Desiraju \& Sappington, 2007).

In a nutshell, distributional preferences rely on the idea that subjects draw - in addition to the utility they gain from their own monetary payoff - disutility from inequality between payoffs. For the formal characterization of the fairness models, let us denote the interdependent preferences of subject $i$ interacting with another subject $-i$ in a group as $u_{i}\left(\pi_{i}, \pi_{-i}\right)$. Thus, $i$ 's utility depends on his or her own payoff and on the payoff of the other group member, $\pi_{-i}$. Crucially for all models of inequity aversion (e.g., Fehr 65 Schmidt, 1999, Bolton 8 Ockenfels, 2000) the utility function of an inequity-averse responder, $u_{i}\left(\pi_{i}, \pi_{-i}\right)$, must satisfy the following two conditions:

$$
\begin{gathered}
\frac{\partial u_{i}\left(\pi_{i}, \pi_{-i}\right)}{\partial \pi_{-i}}=0 \text { if } \pi_{i}=\pi_{-i} \text { and } \\
\frac{\partial^{2} u_{i}\left(\pi_{i}, \pi_{-i}\right)}{\partial \pi_{-i}^{2}}<0 \text { if } \pi_{i}=\pi_{-i} .
\end{gathered}
$$

Thus, for a given payoff of $i$, her utility is maximized if all other group members receive the same payoff.

For my further analysis, I will rely on the second approach, intentionbased preferences. Referring to intention-based preferences, subjects gain utility by responding reciprocally. They respond kindly to perceived kind actions by others or they respond unkindly to perceived unkind actions by others. Reciprocity, in contrast to distributional preferences, focuses on the intention of an action. Similar consequences might be perceived quite differently considering the way the results are reached. Actions that are perceived as kind lead to kind responses, while unkind actions trigger unkind responses.

Apparently, defining (un)kindness is a very complicated thing. Essentially, intentional models measure the utility gained from reciprocity as the product of two terms (e.g., Falk 8 Fischbacher, 2006). The first term, the kindness term $\phi$, represents the perceived treatment of a subject by another player. The term $\phi \in\left[l^{-}, l^{+}\right]$where $l^{-} \in \mathbb{R}^{-}$and $l^{+} \in \mathbb{R}^{+}$(typically, 
$\left.l^{-}+l^{+}=0\right)$, where $\phi$ is strictly increasing the more kindly treatments are perceived; $\phi=0$ captures a treatment that is perceived neither unkindly nor kindly. The second term, the reciprocation term $\psi$, assesses the reaction of the subject to that treatment. Again, the term $\psi \in\left[k^{-}, k^{+}\right]$where $k^{-} \in \mathbb{R}^{-}$ and $k^{+} \in \mathbb{R}^{+}$(typically, $k^{-}+k^{+}=0$ ), $\psi$ is strictly increasing the more kindly the subject responds; $\psi=0$ captures a reaction that is perceived neither unkindly nor kindly. Intention-based preferences rely on the product of the two terms so that one can write $u_{i}:=u_{i}\left(\pi_{i}, \phi \psi\right)$. For intention-based preferences (e.g., Dufwenberg 8 Kirchsteiger, 2004, Falk 86 Fischbacher, 2006), the utility function must satisfy the following two conditions:

$$
\begin{gathered}
\frac{\partial u_{i}\left(\pi_{i}, \phi \psi\right)}{\partial \psi}<0 \text { if } \phi<0 \text { and } \\
\frac{\partial u_{i}\left(\pi_{i}, \phi \psi\right)}{\partial \psi}>0 \text { if } \phi>0 .
\end{gathered}
$$

Thus, for a given payoff of $i$, his or her utility is maximized if he or she responds kindly to an action perceived as kind, while he or she responds unkindly to an action perceived as unkind. Obviously, both terms crucially depend on the subject's belief concerning the action of the other subject. I refer to this belief as the first order belief of the subject. Furthermore, kindness and reciprocation essentially depend on the subject's belief about the belief of the other subject concerning the action the subject will choose. I refer to this belief as the second order belief of the subject. For instance, the fact that the other player does not contribute to a public good game (as introduced in the second example) may be perceived unkindly if the subject believes that the other player believes that the subject contributes to the public good game. However, if the subject believes that the other player believes that the subject will not contribute, the action may not be perceived unkindly.

Notice that I have presented the intention-based preference approach in a sequential form, that is, there is a temporal order among actions and reactions. Notwithstanding, intention-based preferences lead to equilibrium predictions for simultaneous actions (see Rabin, 1993). Subjects anticipate the behavior of their counterparts and respond kindly or unkindly. I would like to stress that the intention-based preference approach does not predict reciprocal behavior for all subjects. The approach models a tradeoff between the utility gained from the monetary payoff and the utility gained from behaving reciprocally (equations (9) are partial derivatives). For some subjects, there exists almost no tradeoff, since the utility due to reciprocal behavior is 
of minor importance compared with the monetary utility. Overall, there is evidence that increasing the costs for being reciprocal reduces the proportion of subjects who behave in this way; fairness seems to be price-sensitive (e.g., see Zwick \& Chen, 1999).

Speculating over the equilibria for intention-based preference approach leads to a large variety of scenarios (the subsequent section will offer more than speculations). With respect to the example of team work within the firm, workers who perceive the "take-it-or-leave-it" offer as unkind respond unkindly, either by not accepting the contract or by reducing work effort. On the other hand, the firm owner could increase the payoffs in equation (7) for the case that $x(a)<x\left(a^{*}\right)$ from 0 to some $\kappa_{i}<k_{i}$. Assuming pure monetary preferences, the payoff $\kappa_{i}$ is not realized (technically speaking, $\kappa_{i}$ is an off-equilibrium payment), since workers choose $a^{*}$. However, increasing the off-equilibrium payment may increase the kindness of the "take-it-or-leave-it offer". In general, reciprocity is a complicated thing. What is considered kindly, what unkindly? These complications are reduced within firms. Corporate actors are characterized by long-term interactions that help to harmonize first and second order beliefs. The next section shows an example where repeated interaction creates some material, but non-contractual value, which can be explained by the fact that subjects have interdependent preferences.

\section{The composition of the firm}

In this section, I will consider the results of laboratory experiments conducted by Fehr, Klein and Schmidt (2007). Particularly, the efficiency of incentive contracts are compared with bonus payment schemes. Both types of contracts can be transferred in the framework introduced by Holmstrom (1982). Consider a firm with only one employee who carries private costs for providing an action for the employer. The employee's action cannot be observed. The Pareto-efficient action $a^{*}$ that maximizes the distance between the production and the corresponding cost for the action is defined analogously to equation (1). In the bonus scheme, the employer announces a desirable $\tilde{a}$ which is not enforceable, in exchange for an unconditional wage. In addition, the employer promises in advance a bonus payment $b$ if $x(a) \geq x(\tilde{a})$. However, the bonus is also not enforceable. Apparently, the bonus contract is doomed to fail. Interacting only once, there is no need for employers to pay the bonus after an action has been delivered. Anticipating that the bonus 
payment promises are nothing more than cheap talk, it is a dominant strategy for the employee to provide the action that incurs the lowest possible cost, denoted as $\underline{a}$. Again by anticipation, the employer's dominant strategy is to offer the lowest possible unconditional wage $\underline{k}:=c(\underline{a})$ leading - theoretically - to minimum efficiency for bonus contracts.

Concerning the incentive contracts, employers announce a desirable $\tilde{a}$ in exchange for a wage $k$. But, Fehr, Klein and Schmidt introduce important modifications from the contract design presented in equation (7). First, there is a small fee $r$ employers have to pay for when choosing the incentive contract. Second, the stepwise payment scheme is obtained via a fine $f$ which has to be paid by the employee if $x(a)<x(\tilde{a})$. Fines have an upper limit $\bar{f}$, and are reimbursed to the employer if implemented. However, there is only a probability $p<1$ that the fine is executed if the action falls below the desirable $\tilde{a}$. Thus, employees can calculate the expected costs for choosing $a<\tilde{a}$ as $p f$, which is at most $p \bar{f}$. As long as $p f>c(\bar{a})$, it is profitable for the employee to provide the desirable action. Therefore, there is a maximum enforceable $\hat{a}$ which holds $p \bar{f}=c(\hat{a})$. Notice that Fehr, Klein and Schmidt have chosen $\hat{a}$ such that $\hat{a}<a^{*}$. In summary, the orthodox theoretical analysis yields for the the bonus contract an action choice of $\underline{a}$, while $\hat{a}$ for the incentive contract with $\underline{a}<\hat{a}<a^{*}$.

Formally, the employer chooses to offer either a bonus contract or an incentive contract. Let us define the dummy variable $\mu$ as $\mu=1$ if the incentive contract is chosen, and $\mu=0$ if the bonus contract is chosen. Furthermore, the employer announces the desirable action $\tilde{a}$ and, if the incentive contract is chosen, the fine $f$. Thus, the employer's expected profit, $\pi_{o}(a)$, is

$$
\pi_{o}(a)=x(a)-k-(1-\mu) b+\mu \begin{cases}p f-r & \text { if } a<\tilde{a} \\ -r & \text { if } a \geq \tilde{a}\end{cases}
$$

The corresponding expected profit of the employee, $\pi_{e}(a)$, is

$$
\pi_{e}(a)=k-c(a)+(1-\mu) b-\mu \begin{cases}p f & \text { if } a<\tilde{a} \\ 0 & \text { if } a \geq \tilde{a} .\end{cases}
$$

Experimental participants have played the game for ten consecutive periods with randomly matched partners. Participants have interacted only once with the same partner. The probability $p$ remained constant throughout the entire experiment at $1 / 3$. 
The experimental results are very different from the theoretical expectations. The overwhelming majority of employers has preferred the bonus contract, while incentive contracts have been rarely chosen. Across the experimental periods, between roughly eighty and ninety-five percent of all contracts are bonus contracts. Employers have a clear preference for the bonus contract. More importantly, the average efficiency of the production under the bonus contract scheme exceeds the efficiency of production under the incentive contract scheme considerably. Disregarding the fee $r$ for the choice of the incentive contract, theoretical predictions for $\hat{a}$ lead to 45 percent, while for $\underline{a}$ they are 12.5 percent of the maximal production efficiency. In contrast, the incentive contract yields on average 19.25 percent, and the bonus contract yields on average 56 percent of the maximal production efficiency. Therefore, the laboratory experiments find approximately the opposite results from the theoretical predictions. This result challenges the theoretical analysis by Holmstrom (1982), too. Remember that the interactions have taken place among strangers in a anonymous experiment. Thus, this example rather underestimates than overestimates the real-world phenomena of repeated interactions in firms.

Moreover, there are no strategic reasons that can explain the employers' preference for bonus contracts or the bad performance of the incentive contracts in terms of production efficiency. It is important to stress that both types of players, employers and employees, are strictly better off under the bonus contract compared with the incentive contract, whereas the orthodox perspective of the firm predicts a minimum of production efficiency for the bonus contract. The actual results show the crucial influence of interdependent preferences for interactions within corporate actors. Fehr, Klein and Schmidt (2007) are able to show that their laboratory results correspond with the distribution of an inequity aversion parameter within the population of players that has been observed in previous experiments (e.g., Fehr \& Schmidt, 1999). Also, a short analysis of the contract schemes for intentionbased preference models reveals the advantages of the bonus contract scheme in terms of production efficiency. This will be done in the following.

For the analysis, I have to specify the intention-based preference function in greater detail. The preference function has to provide a tradeoff between own material payoffs and reciprocal behavior. Therefore, I assume that the function has two simple additive terms. The first term is a function of the individual payoff; the second term formalizes reciprocity. If the second term is zero, that is, if individuals act on their own, they behave in accordance with 
the orthodox preference model. In order to model reciprocity, I need reference points which determine expectations for kind versus unkind actions, and kind versus unkind reactions. Notice that - in contrast to the orthodox theory - the majority of employers choose $k=k_{0}>\underline{k}$ under the bonus contract scheme. Therefore, they implicitly define a reference point for the minimum desirable action $a_{0}$, for which it must hold that $k_{0}=c\left(a_{0}\right)$. Under the incentive contract scheme, the reference point $a_{0}$ equals $\tilde{a}$. Here, the second reference point is $\underline{a}$. In order to evaluate the kindness of the contracts, one has to compare the monetary surplus, the contract offers with the additional working costs for accomplishing the contract. The monetary surplus is $k-c(\tilde{a})$, while the additional costs are $c(\tilde{a})-c(\underline{a})$ for the incentive contract; if $k-c(\tilde{a})>c(\tilde{a})-c(\underline{a})$, the contract is kind. Likewise, evaluating the kindness of a bonus contract compares the monetary surplus $k-c(\tilde{a})$ with the additional costs $c(\tilde{a})-c\left(a_{0}\right)$; if $k-c(\tilde{a})>c(\tilde{a})-c\left(a_{0}\right)$, the contract is kind. Thus, the incentive contract is per se more likely to be perceived unkindly, since $c\left(a_{0}\right)>c(\underline{a})$. According to equation (9), employees increase their utility by responding unkindly, that is, they fail to provide the desirable action, to a perceived unkind contract offer. If the tradeoff between the monetary payoffs and the utility gained from reciprocal response favors the reduction of actions, employees will do so.

To summarize this short analysis, I can show that the probability that the incentive contract is perceived unkindly is per se higher than the corresponding probability for the bonus contract. Notwithstanding, this means that bonus contracts are per se more likely to be accomplished. This depends on the actual wages, boni and the individual tradeoff between monetary payoffs and reciprocal responses. Yet, the experimental evidence that a majority of players prefers bonus contracts supports this claim.

\section{Conclusion}

What is the nature of the firm? Orthodox economic theory suggests that the firm is nothing more than distribution of property rights on the production assets and a corresponding nexus of contracts which is based on the property rights. By doing so, the firm is decomposed into a bundle of cooperating individuals. Indeed, this so-called property rights approach has helped enormously to understand the structure of economic interactions which take place in firms (see, e.g., Hart, 1988) and in corporate actors in general. The results presented in Section 1 have attempted to indicate the importance of 
contractual designs for the production efficiency. Yet, the orthodox economic approach suggests that this is essentially a complete picture of the firm. There is substantial critique on this perspective. Most importantly, firms create some immaterial values like reputation or well-rehearsed production routines which are non-transferrable and non-contractual. Employees seem to provide these values voluntarily, while wages reflect non-contractual attainments. Employees and employers exchange mutually gifts (Akerlof, 1982) which create the extra value of the firm.

These elements have been incorporated into the economic theory by formalizing interdependent preferences. Individual interests change systematically if the individuals are assembled in groups. It is important to stress that the concept of interdependent preferences does not leave the economic methodology, since all actions can be traced back to individual interests. Interdependent preferences nest orthodox economic preferences; yet, the scope of individual interests is extended if individuals find themselves assembled in groups. This article has attempted to introduce at least some of these aspects by introducing two prominent interdependent preference models, inequityaverse preferences and intention-based preferences. In a nutshell, inequityaverse preferences predict that differences among individual and other people's payoffs cause disutility to subjects. Intention-based preferences assume that subjects have a preference for responding reciprocally. They respond kindly to perceived kind actions by others, or they respond unkindly to perceived unkind actions by others. In presenting some experimental evidence (Fehr, Klein \& Schmidt, 2007), I have tried to emphasize the importance of interdependent preferences for interactions within firms. A simply analysis of contract schemes (bonus versus incentive contracts) has shown how misleading the incomplete orthodox economic approach can be. Results of laboratory experiments support this perspective.

However, interdependent preferences are only one aspect among many. Still, there is a need to represent firms more accurately in economics. The picture of firms we yield is more distinctive. Firms are not simply organized cooperations. Rather, firms and corporate actors create additional values. These values are not attached to individual members of corporate actors. Further research is needed to provide a more accurate picture of firms and corporate actors and the values they initiate. 


\section{References}

Bolton, G.E. \& A. Ockenfels (2000), ERC: A theory of equity, reciprocity, and competition, American Economic Review 90, 166-193.

Cabral, L.M.B. (2000), Stretching firm and brand reputation, The Rand Journal of Economics 31, 658-673

Coase, R. (1937), The nature of the firm, Economica 4, 386-405.

Demougin, D., C. Fluet \& C. Helm (2006), Output and wages with inequality averse agents, Canadian Journal of Economics 39, 399-413.

Desiraju, R. \& D. Sappington (2007), Equity and adverse selection, Journal of Economics and Management Strategy, forthcoming.

Dufwenberg, M. \& G. Kirchsteiger (2004), A theory of sequential reciprocity, Games and Economic Behavior 47, 268-298.

Falk, A. \& U. Fischbacher (2006), A theory of reciprocity, Games and Economic Behavior 54, 293-315.

Fehr, E., A. Klein \& K. Schmidt (2007), Fairness and contract design, Econometrica 75, 121-154.

Fehr, E. \& K. Schmidt (1999), A theory of fairness, competition, and cooperation, Quarterly Journal of Economics 114, 817-868.

Fehr, E. \& K. Schmidt (2006), The economics of fairness, reciprocity and altruism - Experimental evidence and new theories, in S.-C. Kolm \& J.M. Ythier (eds.), Handbook of the Economics of Giving, Altruism and Reciprocity, Volume 1, Amsterdam: Elsevier, 615-692.

Grossman, S. \& O. Hart (1986), The costs and benefits of ownership: A theory of vertical and lateral integration, Journal of Political Economy 94, 691-719.

Güth, W., R. Schmittberger \& B. Schwarze (1982), An experimental analysis of ultimatum bargaining, Journal of Economic Behavior and Organization 3, 367-388. 
Hart, O. (1988), Incomplete contracts and the theory of the firm, Journal of Law, Economics, and Organization 4, 119-139.

Hart, O. \& J. Moore (1990), Property rights and the nature of the firm, The Journal of Political Economy 98, 1119-1158.

Holmstrom, B. (1982), Moral hazard in teams, The Bell Journal of Economics 13, 324-340.

Isaac, R., K. McCue \& C. Plott (1985), Public good provision in an experimental environment, Journal of Public Economics 26, 51-74.

Jensen, M.C. \& W.H. Meckling (1976), Theory of the firm: Managerial behavior, agency costs and ownership structure, Journal of Financial Economics 3, 305-360.

Kagel, J.H. \& A.E. Roth (eds.) (1995), The Handbook of Experimental Economics, Princeton, N.J.: Princeton University Press.

Rabin, M. (1993), Incorporating fairness into game theory and economics, American Economic Review 83, 1281-1302.

von Siemens, F. (2005), Fairness, adverse selection, and employment contracts, working paper 2005-14, München: Ludwig Maximilians University.

Sobel, J. (2005), Interdependent preferences and reciprocity, Journal of Economic Literature 43, 392-436.

Zwick, R. \& X.-P. Chen (1999), What price fairness? A bargaining study, Management Science 45, 804-823. 